\title{
The pattern recognition receptor Nod1 activates CCAAT/enhancer binding protein $\beta$ signalling in lung epithelial cells
}

\author{
J.L. Barton*,*, T. Berg*," L. Didon* and M. Nord*,+
}

ABSTRACT: The innate immune receptor nucleotide-binding oligomerisation domain protein 1 (Nod1) recognises peptidoglycan containing meso-diaminopimelic acid found in all Gramnegative and some Gram-positive bacteria. Nod1 has been shown to activate nuclear factor (NF)кB. The aim of the present study was to examine the expression of Nod1 in the lung, particularly in lung epithelial cells, and to investigate the activation of CCAAT/enhancer binding protein (C/EBP) transcription factors downstream of the Nod1 receptor in these cells.

The expression of Nod1 in mouse lung was examined using immunohistochemistry. A tissue array was used to determine the expression pattern in the human lung. Signalling downstream of Nod1 was examined in the human lung epithelial cell type, BEAS-2B, by electrophoretic mobility shift assay and reporter gene activation.

Nod1 expression was seen in various cell types in the lung, including epithelial cells. Activation of Nod1 in these cells resulted in modest activation of NF-кB, together with strong activation of the C/EBP transcription factors, particularly C/EBP $\beta$. This activation appears to be independent of de novo protein synthesis.

The present study showed that nucleotide-binding oligomerisation domain protein 1 is expressed in lung epithelial cells. The results demonstrate a novel pathway downstream of the nucleotide-binding oligomerisation domain protein 1 receptor in these cells and suggest that $\mathrm{C} /$ EBP $\beta$ may play a role in immune responses to meso-diaminopimelic acid-containing bacteria in the lung.

KEYWORDS: CCAAT/enhancer binding protein, innate immune system, intracellular signalling, lung epithelium, nucleotide-binding oligomerisation domain protein 1 receptor, transcription factors

$\mathrm{n}$ the lung, epithelial cells provide a first line of defence to protect the host against invading pathogens. A second line of defence is provided by the host's pattern recognition receptors, which sense pathogen-associated molecular patterns (PAMPs) and activate signals that lead to the destruction of the invading bacteria. PAMPs from bacteria and viruses are detected by toll-like receptors (TLR) [1]. It has recently been demonstrated that bacterial peptidoglycan (PGN) is detected by the intracellular nucleotide-binding oligomerisation domain protein (Nod) $1[2,3]$ and Nod2 [4] receptors, rather than by TLR as was previously thought [5]. Nod1 recognises PGNrelated molecules that contain meso-diaminopimelic acid (meso-DAP) [2, 3], which are found in all Gram-negative and some Gram-positive bacteria, whereas Nod2 recognises muramyldipeptide MurNAc-L-Ala-D-iso-Gln (MDP) [4], which is found in the PGN of virtually all bacteria.
In response to pathogen recognition, epithelial cells activate signalling pathways that lead to the production of cytokines, chemokines and antimicrobial peptides, which participate in pathogen removal [6]. Streptococcus pneumoniae, Pseudomonas aeruginosa, Staphylococcus aureus, Mycobacterium tuberculosis and Moraxella catarrhalis, which are all important pulmonary pathogens, have been shown to result in the production of chemotactic mediators from lung epithelial cells [7-11]. It has been demonstrated that many of these pathogens are recognised by the Nod1 receptor [12-14]. Epithelial-derived chemotactic mediators are central to the recruitment of neutrophils to the airways, and thus play a key role in the pulmonary innate immune response.

Following activation, the Nod1 receptor has been shown to activate the transcription factor nuclear factor $(\mathrm{NF})-\kappa \mathrm{B}[15,16]$ resulting in transcription

\section{AFFILIATIONS}

*Dept of Medicine-Solna, Division for Respiratory Medicine, Karolinska Institute, Karolinska University Hospital, Stockholm, and, ${ }^{+}$Discovery Medicine, Medical Science, Astra Zeneca R\&D, Lund, Sweden.

\# Leeds Institute of Molecular Medicine, University of Leeds, Leeds, UK.

'Saban Research Institute, Children's Hospital Los Angeles, Los Angeles, CA, USA.

\section{CORRESPONDENCE}

\section{J.L. Barton}

Leeds Institute of Molecular Medicine

Level 6

Wellcome Trust Brenner Building

St James's University Hospital

Beckett Street

Leeds LS9 7TF

UK

Fax: 441133438502

E-mail: J.L.Barton@leeds.ac.uk

Received:

November 052006

Accepted after revision:

May 292007

\section{SUPPORT STATEMENT}

The study was supported by grants from the Swedish Research Council Medicine (grant No. 14677), the Swedish Heart-Lung Foundation (grant No. 20050443), Stockholm County Council, Åke Wiberg, Magnus Bergvall and Konsul Th. C. Bergh Research Foundations and the Karolinska Institute (all Stockholm Sweden).

STATEMENT OF INTEREST None declared. 
of inflammatory genes. However, CCAAT/enhancer binding protein $(\mathrm{C} / \mathrm{EBP}) \beta$ and $\mathrm{C} / \mathrm{EBP} \delta$ transcription factors, which are expressed in airway epithelial and alveolar type-II cells [17, 18], are also known to play a role in expression of inflammatory genes [19]. The current authors hypothesised that C/EBPs are activated downstream of the Nod1 receptor and, therefore, could play a role in innate immune responses to bacteria in the lung. The present study demonstrates that Nod1 is expressed in lung epithelial cells and that C/EBP $\beta$ and, to a lesser extent, C/EBP $\delta$ are activated by this receptor.

\section{METHODS}

\section{Constructs and reagents}

The rabbit anti-human Nod1 antibody (Nod11-S) was obtained from Alpha Diagnostics (San Antonio, TX, USA). Peroxidaselabelled goat anti-rabbit antibody for immunohistochemistry was supplied by Vector Laboratories (Burlingame, CA, USA). Peroxidase-labelled goat anti-rabbit antibody was used for Western blotting (Amersham Biosciences, Little Chalfont, UK). The anti-C/EBP $\beta$ (sc-150 x) and anti-C/EBP $\delta$ (sc-636 x) were both obtained from Santa Cruz Biotechnology (Santa Cruz, CA, USA). The lung tissue array (LUD151) was purchased from Pantomics (San Francisco, CA, USA). A cDNA clone containing the entire human Nod1 cDNA from the I.M.A.G.E. Consortium [LLNL] clone 4338930 was obtained via HGMP, Cambridge, UK. The C/EBP-firefly luciferase reporter constructs have been previously described [20]. Lipopolysaccharide (LPS; serotype 026:B6) was purchased from Sigma-Aldrich (Stockholm, Sweden). The synthetic tripeptide, L-Ala- $\gamma$-D-Glumeso-DAP (TriDAP), has been described previously [21].

\section{Immunohistochemistry}

C57BL6 mice were killed by cervical dislocation and lungs were fixed by intratracheal inflation with $4 \%$ paraformaldehyde as previously described [22]. Antigens were retrieved by microwaving in $10 \mathrm{mM}$ citrate buffer at $\mathrm{pH}$ 6.0. After washing in PBS, samples were incubated for 30 min with $0.3 \% \mathrm{H}_{2} \mathrm{O}_{2}$ in PBS. Following a 1-h incubation in buffer A (PBS containing $0.3 \%$ Tween and 5\% goat serum), samples were incubated overnight at $4{ }^{\circ} \mathrm{C}$ in buffer A containing a 1:500 dilution of the rabbit anti-human Nod1 antibody. The samples were washed for $1 \mathrm{~h}$ in PBS containing 0.3\% Tween, and then incubated for $2 \mathrm{~h}$ in buffer A containing a 1:200 dilution of peroxidaselabelled goat anti-rabbit immunoglobulin G. After washing, antigen-antibody complexes were detected with the Vectastain ABC-kit (Vector Laboratories, Burlingame, CA, USA) and counterstained with haematoxylin. Staining was performed on lung tissue from four different mice. The lung tissue array was stained as above with the exception that the primary rabbit anti-human Nod1 antibody was used at a 1:1,000 dilution.

\section{Cell culture and transfection}

BEAS-2B cells (ATCC, Manassas, VA, USA) were cultured in RPMI 1640 medium supplemented with $2 \mathrm{mM}$ L-glutamine, $10 \%$ foetal bovine serum, $100 \mathrm{IU} \cdot \mathrm{mL}^{-1}$ penicillin and $0.1 \mathrm{mg} \cdot \mathrm{mL}^{-1}$ streptomycin (Gibco, Paisley, UK). When preparing nuclear extracts from transfected cells, the cells were plated $24 \mathrm{~h}$ prior to transfection on $75 \mathrm{~cm}^{2}$ flasks. Cells were transfected with Fugene 6 (Roche, Penzberg, Germany) according to the manufacturer's instructions using a Fugene 6/DNA ratio of $3: 1$, and left for $24 \mathrm{~h}$ prior to preparation of nuclear extracts. Typically, transfection efficiencies were 10$20 \%$, as determined by control transfection with a green fluorescent protein (GFP)-expressing construct.

\section{Preparation of nuclear extracts and electrophoretic mobility shift assays}

The preparation of nuclear extracts has been previously described [17]. Double-stranded synthetic oligonucleotides harbouring a consensus C/EBP- (underlined; 5' CGG GAT CCA TTG CGC AAT GGA TCC 3') or NF-кB- (underlined; 5' AGT TGA GGG GAC TTT CCC AGG $3^{\prime}$ ) binding site were used as probes. The probes were end-labelled using $\left[\gamma_{-}{ }^{32} \mathrm{P}\right]$ adenosine triphosphate and $\mathrm{T} 4$ polynucleotide kinase (Amersham Biosciences). Electrophoretic mobility shift assays (EMSA) were performed as previously described [17] using 1$6 \mu \mathrm{g}$ of nuclear extracts. Where appropriate, $1 \mu \mathrm{L}$ of polyclonal antibodies, anti-C/EBP $\beta$ (sc-150 x) or anti-C/EBP $\delta$ (sc-636 x; both from Santa Cruz Biotechnology) were included. EMSA were carried out using nuclear extracts from a minimum of three experiments and representative gels are shown below.

\section{Western blotting}

For Western blotting, nuclear proteins (3-15 $\mu \mathrm{g})$ were resolved on $12 \%$ SDS-PAGE gels and then transferred to Protran nitrocellulose membrane (Schleicher and Schuell, Dassel, Germany). To verify equal loading of samples and even transfer to the membrane, the membrane was stained with Ponceau S stain. Following this, the membrane was blocked in Tris-buffered saline with $0.1 \%$ Tween (TBST) and 5\% nonfat dried milk powder for $1 \mathrm{~h}$ at room temperature. Membranes were incubated overnight at $4{ }^{\circ} \mathrm{C}$ with $1: 10,000$ dilution of primary polyclonal antibody to $\mathrm{C} / \mathrm{EBP} \beta$ or $\mathrm{C} / \mathrm{EBP} \delta$, in TBST with $5 \%$ nonfat dried milk powder. Following washing in TBST, primary antibodies were detected using anti-rabbit peroxidase-labelled antibody diluted 1:10,000 in TBST containing $5 \%$ nonfat dried milk powder for $2 \mathrm{~h}$ at room temperature. After washing, the secondary antibody was detected using enhanced chemiluminescence Western Blotting detection reagent (Amersham Biosciences). Western blots were carried out using nuclear extracts from a minimum of three experiments and representative blots are shown below.

\section{C/EBP reporter gene assays}

BEAS-2B cells were plated at $12 \times 10^{4}$ per well of a 24 -well plate in $300 \mu \mathrm{L}$ medium. Cells were transfected with $1.2 \mu \mathrm{g}$ DNA using Fugene 6 (Roche) according to the manufacturer's instructions. The ratio of Fugene 6/DNA was 3:1. In the case of co-transfections, the ratio of reporter gene to expression plasmid was titred to 9:1 in order to avoid squelching effects. The Fugene/DNA mix was incubated with the cells for $24 \mathrm{~h}$, following which the cells were washed twice with PBS and then lysed with $45 \mu \mathrm{L}$ passive lysis buffer (Biothema, Turku, Finland). The level of expression of luciferase was measured in 30- $\mu \mathrm{L}$ samples in a 96-well plate using the GenGlow Luciferin kit (BioThema). The samples were read on an Orion II luminometer (Berthold, Bad Wildbad, Germany) with a 2-s delay and 10-s read time. Data represent three independent experiments each performed in triplicate. Data were normalised to the basal level seen in unstimulated cells transfected with the reporter gene construct containing an intact C/EBP-site. 


\section{RESULTS}

\section{Nod1 is expressed in mouse and human lung epithelial cells}

Nod1 is expressed in multiple tissues, including human and mouse adult lung [16, 23]. However, the cellular expression pattern in this tissue has not been extensively studied. The present study examined the expression in mouse adult lung by immunohistochemistry using an antibody to Nod1. Nod1 expression was found in airway epithelial cells and in some alveolar type II cells (fig. 1). In the airways, expression was seen all the way down to the bronchoalveolar duct junction and expression was observed in both ciliated and Clara cells. Expression was also detected in alveolar macrophages and in the endothelium (fig. 1). The current authors also examined Nod1 expression in embryonic mouse lung tissue. Nod1 was expressed in this tissue from as early as 14.5 days post-coital (data not shown). The Nod1 antibody was then used on a tissue array to examine expression in human adult lung tissue. The Nod1 expression-pattern in human lung was similar to that observed in mice, with prominent expression in airway epithelial cells (fig. 2). As in the murine lung, expression was seen in endothelial cells, some alveolar type II cells and alveolar macrophages. Therefore, Nod1-expression is observed in resident lung cells with a known role in the early innate responses in the lung [6]. In the array, lung tissue from a patient with chronic bronchitis was included and when Nod1expression was investigated in the present study, decreased Nod1-staining was observed in the airway epithelium (fig. 2d).

\section{Activation of transcription factors downstream of Nod1}

As Nod1 expression was prominent in both human and mouse airway epithelium, the human BEAS-2B bronchial epithelial cell line was used to explore the role of Nod1 in the airways. These cells have been reported to express Nod1 [24] and, therefore, would be expected to express the signalling components required for Nod1 signalling. The cells were transiently transfected with a Nod1-expression clone and $24 \mathrm{~h}$ after transfection, nuclear activation of the transcription factors $\mathrm{NF}-\kappa \mathrm{B}$ and $\mathrm{C} / \mathrm{EBP}$ was assessed by EMSA. It has previously
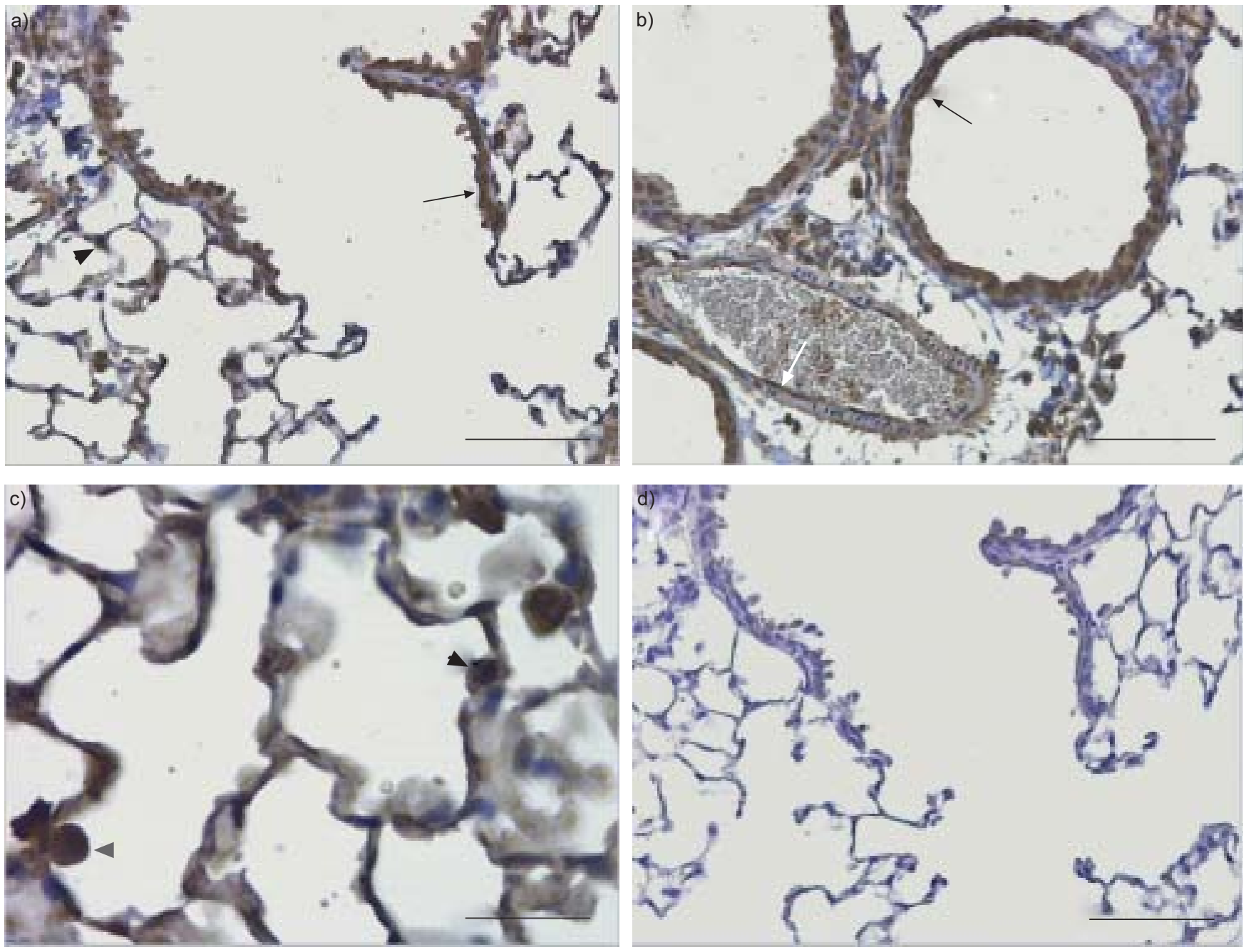

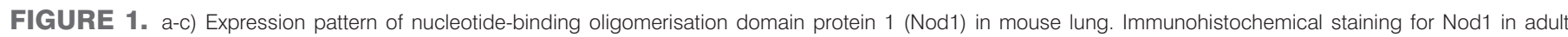

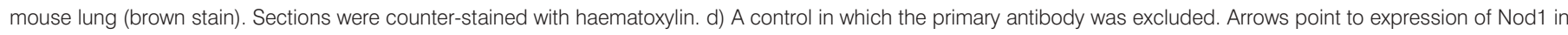

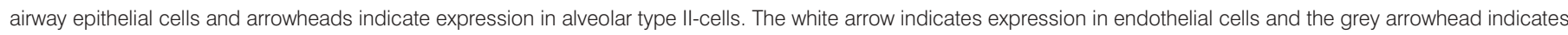
Nod1 expression in alveolar macrophages. Scale bars: a, b, d) $200 \mu \mathrm{m}, \mathrm{c}) 100 \mu \mathrm{m}$. 

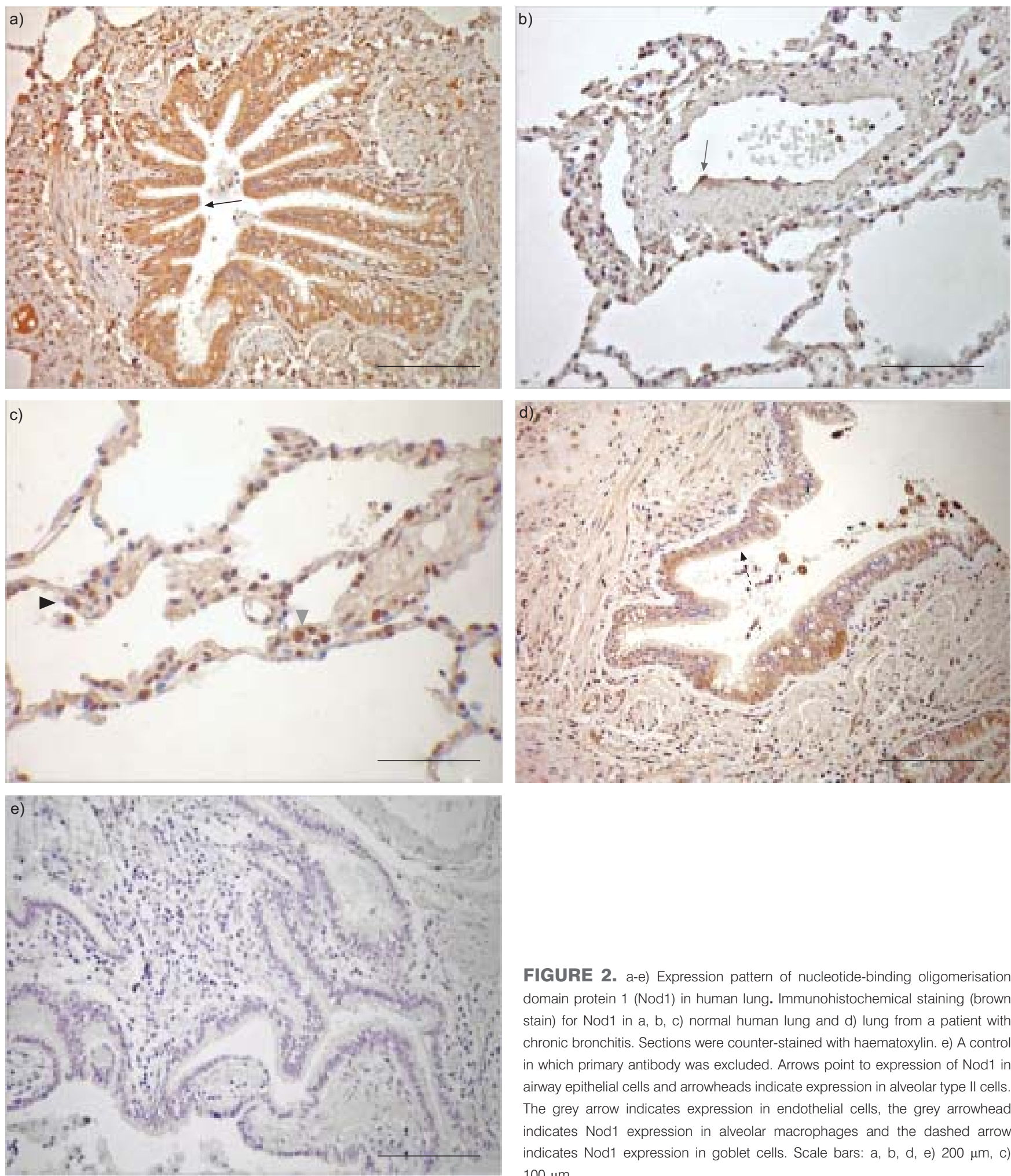

FIGURE 2. a-e) Expression pattern of nucleotide-binding oligomerisation domain protein 1 (Nod1) in human lung. Immunohistochemical staining (brown stain) for Nod1 in a, b, c) normal human lung and d) lung from a patient with chronic bronchitis. Sections were counter-stained with haematoxylin. e) A control in which primary antibody was excluded. Arrows point to expression of Nod1 in airway epithelial cells and arrowheads indicate expression in alveolar type II cells. The grey arrow indicates expression in endothelial cells, the grey arrowhead indicates Nod1 expression in alveolar macrophages and the dashed arrow indicates Nod1 expression in goblet cells. Scale bars: a, b, d, e) $200 \mu \mathrm{m}, \mathrm{c})$ $100 \mu \mathrm{m}$.

been reported that overexpression of Nod1 is sufficient to activate the receptor independently of ligand binding $[15,16]$. Nuclear extracts from transfected cells were incubated with radiolabelled probes containing either NF- $\mathrm{KB}$ or $\mathrm{C} / \mathrm{EBP}$ consensus sites, following which EMSAs were performed. Untransfected BEAS-2B cells and GFP-transfected cells possess some $\mathrm{C} / \mathrm{EBP}$ and NF- $\kappa \mathrm{B}$ activity (data not shown). Activation of Nod1 has previously been described to lead to activation of NF- $\kappa B[15,16]$. As can be seen in figure $3 a$, transfection of cells with a Nod1-expression construct results in a modest increase in NF- $\kappa \mathrm{B}$ binding activity. In contrast, a strong increase in $\mathrm{C} / \mathrm{EBP}$ binding activity in cells transfected with Nod1 was 
observed compared with control transfected cells. These data demonstrate that activation of the Nod1 receptor leads to activation of C/EBPs. As a control for activation of NF- $\kappa B$, cells were stimulated with LPS, which activates the TLR4 receptor and results in NF- $\mathrm{KB}$ binding activity [1]. As expected, $30 \mathrm{~min}$ after LPS stimulation an increase in NF- $\mathrm{B}$ binding activity was observed (fig. 3b). However, following LPS stimulation, no significant change in C/EBP binding was seen.

\section{$C / E B P \beta$ is the main C/EBP family member activated by Nod1}

There is a striking overlap, both in human and mouse lung, in the cellular expression pattern of Nod1 (as observed in the present study) and the C/EBP-transcription factors [17, 18, 25]. Therefore, the activation of $\mathrm{C} / \mathrm{EBP}$ family members downstream of Nod1 was further investigated by EMSA using antibodies to $\mathrm{C} / \mathrm{EBP} \beta$ and $\mathrm{C} / \mathrm{EBP} \delta$. Inclusion of these antibodies revealed that the majority of the $\mathrm{C} / \mathrm{EBP}$-shift in Nod1-transfected cells is due to C/EBP $\beta$ (fig. 4a). C/EBP $\beta$ also comprised the majority of the C/EBP-shift in nontransfected cells. However, C/EBP $\delta$ is also activated in Nod1-transfected cells (fig. 4a), although not as strongly as C/EBP $\beta$. To determine whether the increase in $C / E B P \beta$ binding activity was due to an increase in the levels of $C / E B P \beta$ protein, the amount of C/EBP $\beta$ protein in nuclear extracts from Nod1transfected cells was compared with those from GFP- and pCMV-SPORT6-transfected cells by Western blotting. The level of $C / E B P \beta$ in Nod1-transfected cells was similar to the level in the control-transfected cells (fig. 4b), suggesting that the increase in $\mathrm{C} / \mathrm{EBP} \beta$ binding activity is not due to an increase in $\mathrm{C} / \mathrm{EBP} \beta$ protein levels. However, there did appear to be an increase in the smaller forms of $\mathrm{C} / \mathrm{EBP} \beta$ protein.

\section{Activation of C/EBPs by the Nod1 ligand TriDAP}

Nod1 detects muropeptides from PGN that have a terminal meso-DAP residue (M-TriDAP) but, as the sugar group is not important for its recognition, Nod1 can detect the TriDAP with equal affinity [21]. To determine whether activation of the endogenous Nod1 receptor by its ligand leads to activation of $\mathrm{C} / \mathrm{EBP}$, and also to determine the kinetics of the Nod1-induced C/EBP activation, BEAS-2B cells were stimulated with a synthetic TriDAP molecule and EMSA was performed. Although the Nod1 receptor is located intracellularly there is evidence that addition of the Nod1 ligand to the culture medium of cells is sufficient to activate the receptor [21]. As seen in figure $5 \mathrm{a}, \mathrm{C} / \mathrm{EBP} \beta$ is activated following addition of the TriDAP ligand to the culture media of the cells. Activation of $C / E B P \beta$ occurs within $30 \mathrm{~min}$ of addition of the ligand and can still be seen after $3 \mathrm{~h}$. However, after 24-h stimulation with the ligand, the levels of active C/EBP proteins have returned to normal, if not lower levels. Activation of NF- $\kappa$ B by TriDAP was also investigated. NF- $\mathrm{B}$ was activated within $30 \mathrm{~min}$ of stimulation but, unlike C/EBP, remained activated after $24 \mathrm{~h}$ of stimulation (fig. $5 b$ ). a)

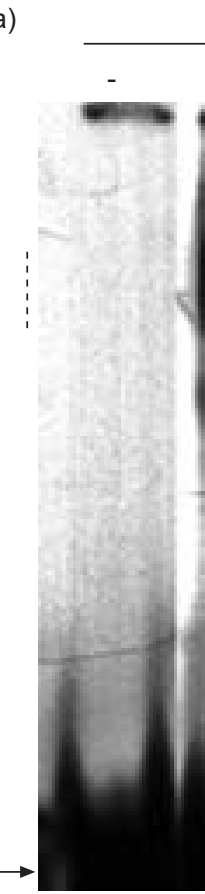

1
$\mathrm{NF}-\mathrm{\kappa B}$

C

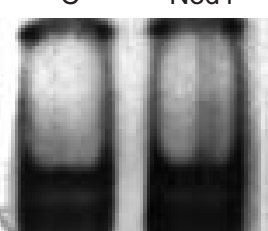

2
C/EBP

C Nod1

b) NF-KB

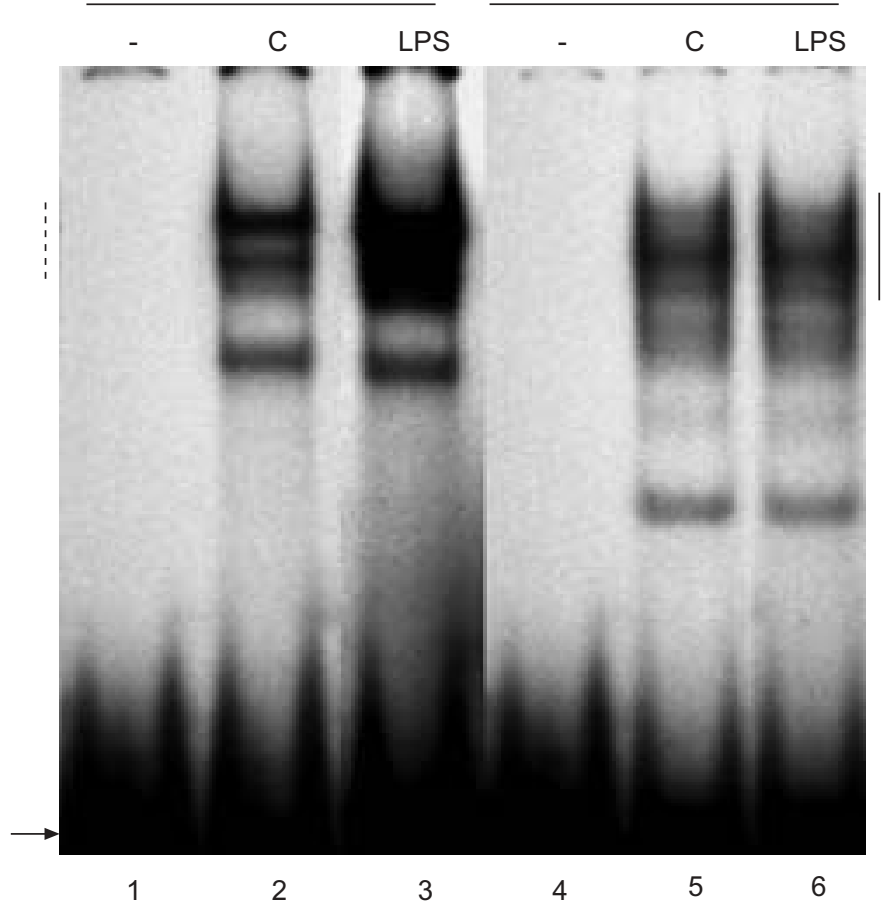

FIGURE 3. a) Nuclear extracts from BEAS-2B cells transfected with a nucleotide-binding oligomerisation domain protein 1 (Nod1) expression plasmid (lanes 3 and 6) or empty expression vector as control (C; lanes 2 and 5) were analysed by electrophoretic mobility shift assay (EMSA) using a nuclear factor (NF)-kB (lanes 1-3) or a CCAAT/ enhancer binding protein (C/EBP; lanes 4-6) consensus oligonucleotide probe. Lanes 1 and 4 contain free probe only. Shifted complexes are indicated with dashed or solid lines for NF-KB and C/EBP, respectively. The arrow indicates migration of free probe. b) Nuclear extracts from BEAS-2B cells untreated (lanes 2 and 5) or treated with $100 \mathrm{ng} \cdot \mathrm{mL}^{-1}$ lipopolysaccharide (LPS; lanes 3 and 6) were analysed by EMSA using a NF-kB (lanes 1-3) or a C/EBP (lanes 4-6) consensus oligonucleotide probe. Lanes 1 and 4 contain free probe only. Shifted complexes are indicated with dashed or solid lines for NF-kB and C/EBP, respectively. The arrow indicates migration of free unshifted probe. 
Again, the current authors determined the amount of $C / E B P \beta$ protein in the nuclear extracts of the stimulated cells. After $30 \mathrm{~min}$ of stimulation, the density of the upper band appeared to be similar to that of the unstimulated cells, even though a significant increase in C/EBP $\beta$ DNA binding was observed, and only a slight increase was seen after $3 \mathrm{~h}$ of stimulation (fig. $5 c$ ). The more defined double band in figure $5 c$ compared with figure $4 \mathrm{~b}$ may be due to cytoplasmic contamination of the nuclear extracts. The rapid increase in C/EBP $\beta$ DNA binding after addition of the Nod1 ligand makes it unlikely that the increased binding is mediated via effects on transcription or protein synthesis, and suggests that post-translational modification of the C/EBP $\beta$ protein underlies this increase. Posttranslational modifications have been shown to regulate the activity of $\mathrm{C} / \mathrm{EBPs}$, with phosphorylation of $\mathrm{C} / \mathrm{EBP} \beta$ being the best characterised [26].

\section{Activation of Nod1 activates C/EBP-dependent transcription}

To determine whether activation of Nod1 results in C/EBPdependent transcription, the present authors co-transfected cells with the Nod1-expression construct and either a C/EBPluciferase reporter construct in which the luciferase reporter gene was under the control of a consensus C/EBP binding site (fig. 6a), or the same construct with a mutated C/EBP site. As shown in figure $6 \mathrm{~b}$, expression of Nod1 resulted in an increase in $\mathrm{C} / \mathrm{EBP}$-dependent transcription. This was confirmed by mutation of the C/EBP site, which abolished the effect. The experiment was repeated in cells where the endogenous Nod1 receptor was activated with the TriDAP ligand. As shown in figure $6 c$, addition of TriDAP to the medium of the cells resulted in an increase in $\mathrm{C} / \mathrm{EBP}$-dependent transcription, and again this increase was prevented by mutation of the $\mathrm{C} / \mathrm{EBP}$ consensus site in the reporter construct. These data demonstrate that the increase in C/EBP activity after activation of the Nod1 receptor is functional with regard to transcriptional activation and, therefore, suggests that C/EBP acts downstream of Nod1.

\section{DISCUSSION}

The present study has demonstrated the presence of Nod1 in multiple cells types of mouse and human lung tissue, including airway epithelial cells. The expression pattern of $\mathrm{C} / \mathrm{EBPs}$ in the lung has recently been described [17, 18, 25]. $\mathrm{C} / \mathrm{EBP} \beta$ is expressed in airway epithelial cells, as well as alveolar type-II cells and alveolar macrophages, and C/EBP $\delta$ is found in the airway epithelium and alveolar type-II cells. Thus, Nod1 and the relevant C/EBPs are co-expressed in vivo in resident cell types with a known role in the early innate responses of the lung [6]. In the human lung tissue array, decreased Nod1 staining intensity was observed in the chronic bronchitic airway epithelium. Decreased C/EBP $\beta$ activity has also been noted in the airway epithelium of patients with chronic bronchitis, and has been implicated in the pathogenesis of this common disease [25]. Together with the activation of C/EBP $\beta$ downstream of Nod1 seen in the current study, these findings demonstrate a correlation that hints at a potential role for these signalling molecules in chronic bronchitis pathogenesis. However, in light of the limited data on the Nod1 expression in chronic bronchitis in the current study, this correlation should be interpreted with care until it is confirmed in future studies.
The role of Nod1 in activating transcription factors of the $\mathrm{C} / \mathrm{EBP}$ family in a human airway epithelial cell line, BEAS-2B, was examined. Strong activation of $C / E B P \beta$ was detected together with a more modest activation of $\mathrm{C} / \mathrm{EBP} \delta$ following overexpression of the Nod1 receptor. Overexpression of Nod1 has been shown to result in oligomerisation of Nod1 through its nucleotide-binding domain and this is thought to activate signalling by bringing the downstream signalling molecules into closer proximity with one another [27]. The current study also confirmed activation of C/EBPs downstream of Nod1
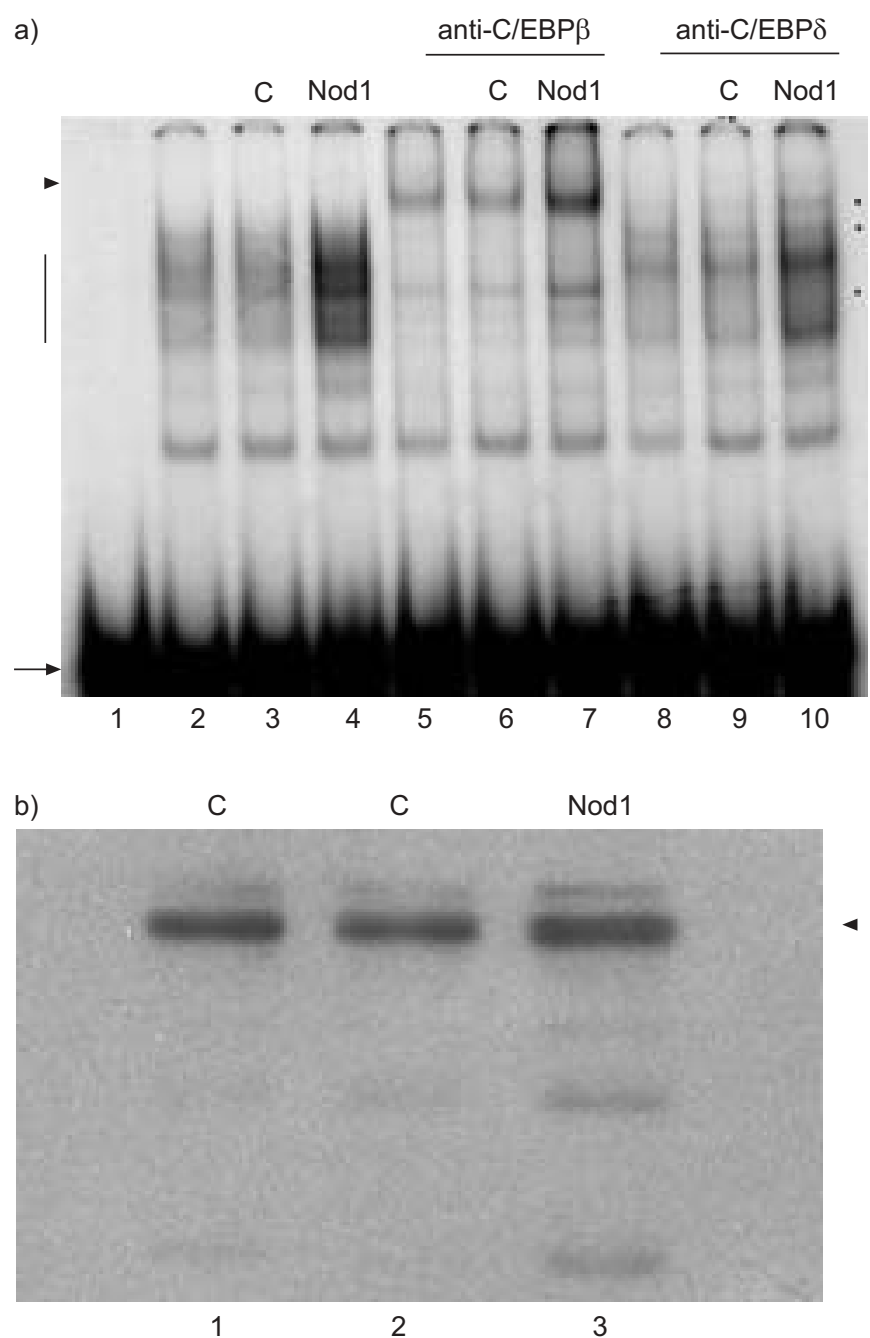

FIGURE 4. a) CCAAT/enhancer binding protein (C/EBP) $\beta$ and C/EBP $\delta$ DNAbinding activity in nuclear extracts from BEAS-2B cells transfected with: a nucleotide-binding oligomerisation domain protein 1 (Nod1) expression plasmid (lanes 4, 7 and 10); controls (C), an empty expression vector, (lanes 3, 6 and 9); or a green fluorescent protein expression plasmid (lanes 2, 5 and 8), were analysed by electrophoretic mobility shift assay using a C/EBP consensus oligonucleotide probe and antibodies against C/EBP $\beta$ (lanes 5-7) or C/EBP $\delta$ (lanes 8-10). The solid line indicates the position of the shifted complex. The arrowhead indicates a supershift upon inclusion of antibody, and the arrow shows migration of free unshifted probe. b) $\mathrm{C} / \mathrm{EBP} \beta$ protein levels in the same extracts as (a) were analysed by Western blotting using a C/EBP $\beta$ antibody. The arrowhead indicates the $p 46 / 49$ isoform of $C /$ EBP $\beta$, the main isoform expressed in human cell lines [26]. C: control. 
a)

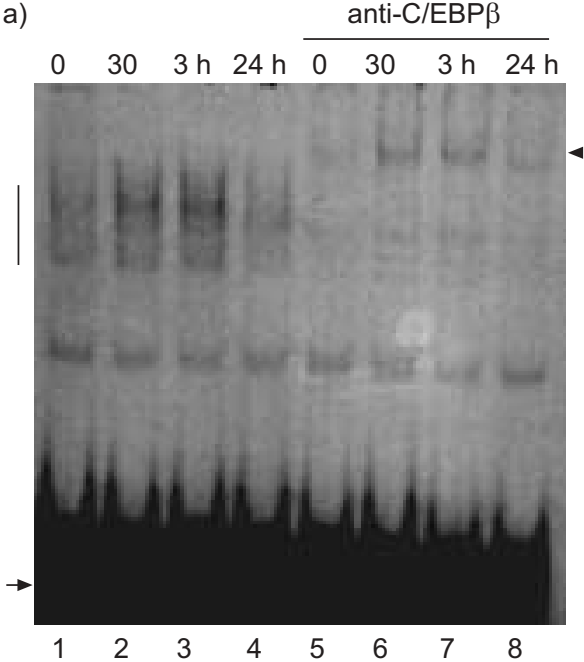

b)

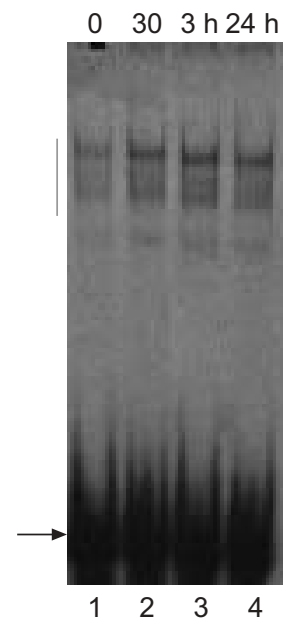

c)

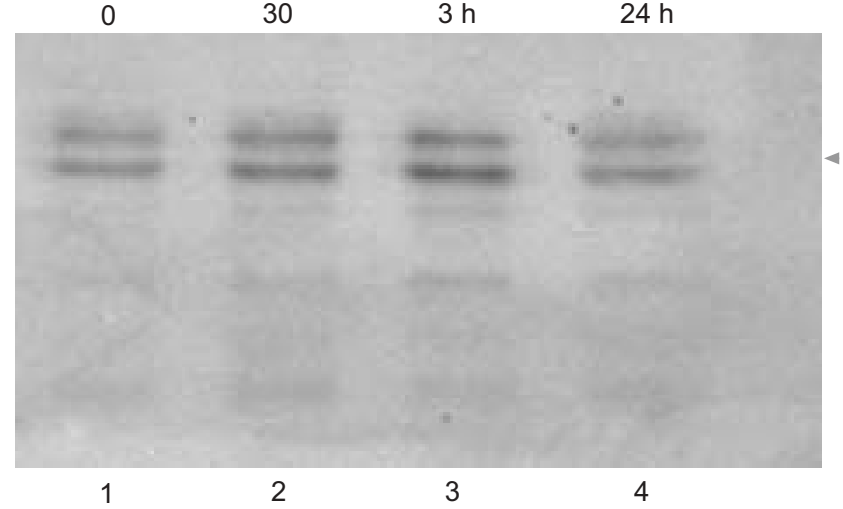

FIGURE 5. a) Nuclear extracts from BEAS-2B cells untreated (0) or treated with $200 \mathrm{nM}$ tripeptide L-Ala- $\gamma$-D-Glu-meso-DAP (TridAP) for between $30 \mathrm{~min}$ and $24 \mathrm{~h}$ were analysed by electrophoretic mobility shift assay (EMSA) using a CCAAT/ enhancer binding protein (C/EBP) consensus oligonucleotide probe and antibodies against C/EBP $\beta$ (lanes 5-8). b) Nuclear extracts from BEAS-2B cells untreated (0) or treated with $200 \mathrm{nM}$ TriDAP for between $30 \mathrm{~min}$ and $24 \mathrm{~h}$ were analysed by EMSA using a nuclear factor- $\mathrm{kB}$ consensus oligonucleotide probe. c) C/EBP $\beta$ protein levels in the same extracts as a) were analysed by Western blotting using a C/EBP $\beta$ antibody. The solid line indicates the position of the shifted complex and the arrow indicates the free unshifted probe. The black arrowhead indicates a supershift upon inclusion of antibody. The grey arrowhead indicates the p46/49 isoform of C/EBP $\beta$, the main isoform expressed in human cell lines [26].

using a Nod1 ligand. To the current authors knowledge, this is the first report of Nod1 receptor signalling activating members of the C/EBP-family. One previous study examining the signalling pathways activated by murabutide (MB), a clinically accepted synthetic derivative of MDP that is now known to be a ligand for Nod2, demonstrated activation of C/EBP [28]. Similar to the present results from stimulation of Nod1, high $\mathrm{C} / \mathrm{EBP} \beta$ activation but weaker and transient activation of NF$\kappa \mathrm{B}$ was observed in MonoMac6 cells activated by MB. Similarly, PGN-polysaccharides from Streptococcus pneumoniae, which are recognised by Nod2 [24], activate NF- $\mathrm{kB}, \mathrm{C} / \mathrm{EBP} \beta$ and activator protein-1 in human bronchial epithelial cells, and lead to the production of interleukin (IL)-8 [29]. Nod1 and Nod2 share common signalling pathways, as both have been a)
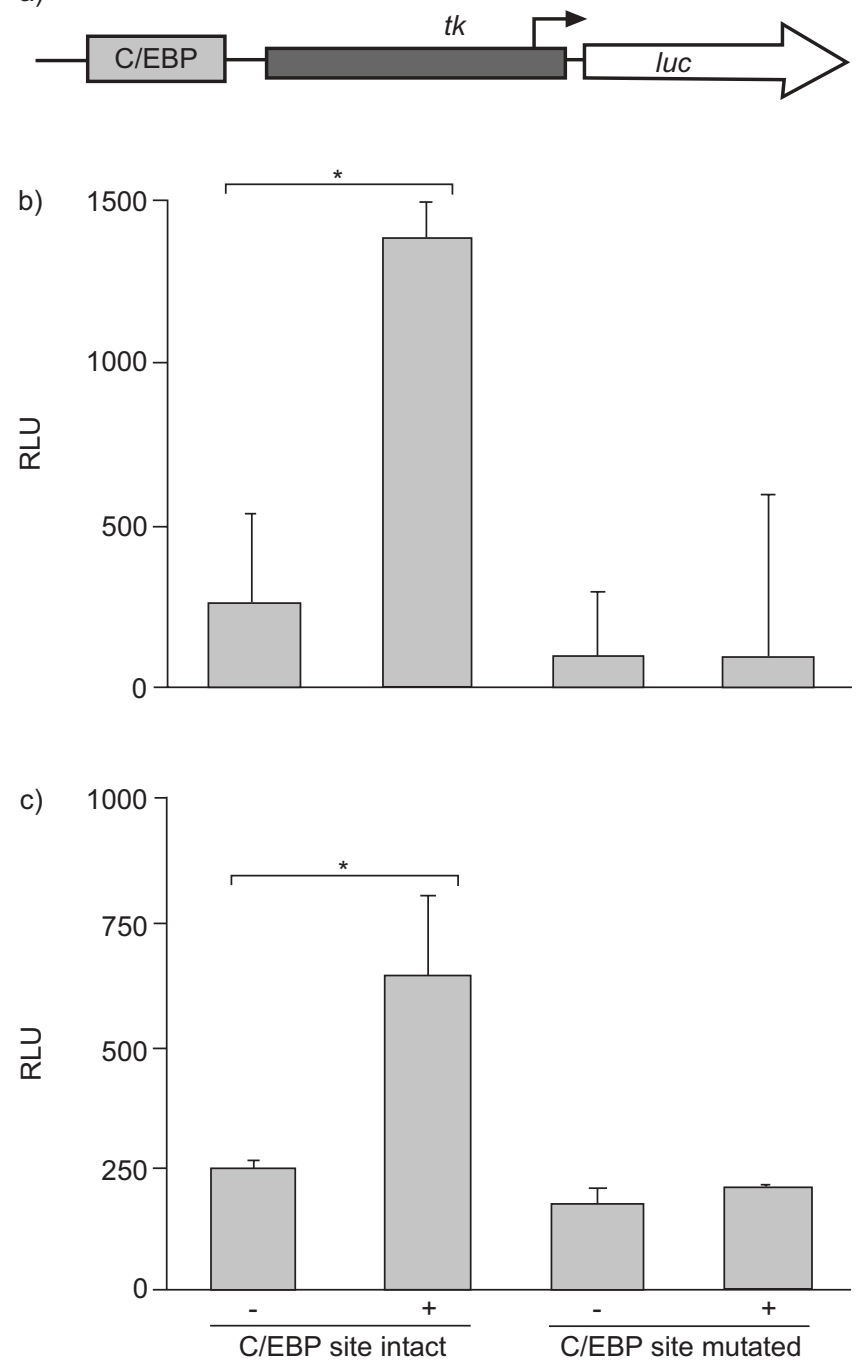

FIGURE 6. a) Schematic representation of the CCAAT/enhancer binding protein (C/EBP) reporter gene. The luciferase reporter gene (luc) is under the control of a consensus C/EBP binding site in front of a minimal herpes simplex virus thymidine kinase (tk) promoter. b) Activation of C/EBP-driven reporter gene activity in BEAS-2B cells by co-transfection of a Nod1 expression plasmid (+) or empty expression vector as control (-). The reporter gene construct contains either a C/EBP-binding site or a C/EBP-binding site that has been inactivated by point mutation. C) C/EBP-driven reporter gene activity in BEAS-2B cells untreated (-) or treated $(+)$ with $200 \mathrm{nM}$ tripeptide L-Ala- $\gamma$-D-Glu-meso-DAP. The reporter gene construct contains either a C/EBP-binding site or a C/EBP-binding site that has been inactivated by point mutation. RLU: relative luciferase units. Error bars indicate SD. *: $p<0.05$, unpaired t-test; $n=3$.

shown to physically interact with RIP-like interacting CLARP kinase (RICK) via a caspase recruitment domain (CARD)CARD interaction $[15,16]$, and signalling downstream of these receptors has been shown to be defective in RICK-deficient cells [30,31]. Activation of RICK has been shown to lead to activation of Jun N-terminal kinase, p38 and extracellular signal-regulated kinase signalling pathways [30,31]. Therefore, it is possible that $\mathrm{C} / \mathrm{EBPs}$ are also activated downstream of the Nod2 receptor. 
To begin to address the mechanism by which Nod1 stimulation leads to activation of $C / E B P \beta$ the levels of $C / E B P \beta$ protein in BEAS-2B cell nuclei were examined. Cells in which Nod1 was activated by over-expressing the Nod1 receptor appeared to contain similar amounts of $C / E B P \beta$ protein to those transfected with empty vector. However, there did appear to be a slight increase in the levels of the truncated form of $\mathrm{C} / \mathrm{EBP} \beta$ in these cells. The truncated form of $\mathrm{C} / \mathrm{EBP} \beta$ behaves as a transcriptional repressor as it lacks the aminoterminal activation domains [32]. However, as Nod1 overexpression still increased $\mathrm{C} / \mathrm{EBP}$-dependent transcription in the reporter gene assay, this does not seem to affect the overall $\mathrm{C} / \mathrm{EBP}$-transactivation potential. The current authors also stimulated cells with the TriDAP ligand and examined the levels of $\mathrm{C} / \mathrm{EBP} \beta$ in the cell nuclei. There appears to be a slight increase in $\mathrm{C} / \mathrm{EBP} \beta$ protein at $3 \mathrm{~h}$ post-stimulation, a timepoint when increased $\mathrm{C} / \mathrm{EBP} \beta$ DNA-binding activity was detected. This increase in protein levels is marginal compared with the striking increase in DNA-binding activity, indicating a mechanism other than increased synthesis of C/EBP $\beta$ protein. The speed with which $C / E B P \beta$ is activated following stimulation of Nod1 also suggests another mechanism. It is possible that, as a result of Nod1 signalling, post-translational modification of C/EBP $\beta$ occurs, resulting in increased DNA binding of this protein. Phosphorylation of C/EBP $\beta$ has been reported to alter its binding ability [26] and since Nod1 can activate several protein kinases, including JNK and p38 mitogen-activated protein kinase $[33,34]$, it is possible that they play a role in regulating the activity of $C / E B P \beta$. Further work is needed to determine the mechanism of $\mathrm{C} / \mathrm{EBP} \beta$ activation by Nod1 and the pathways involved.

A role for $\mathrm{C} / \mathrm{EBP} \beta$ downstream of Nod1 activation by bacterial PAMPs is easy to understand. The $\mathrm{C} / \mathrm{EBP} \beta$ protein was first identified as a protein capable of inducing expression of IL-1 and IL-6. Subsequently C/EBP binding sites have been identified in the regulatory regions of many genes involved in the innate and inflammatory responses [19]. C/EBP transcription factors are expressed in lung epithelial cells [17, 18] and these cells have been shown to express the Nod1 receptor. It has recently been shown $[11,14]$ that Moraxella catarrhalis invades lung epithelial cells and is recognised by Nod1, resulting in production of $\mathrm{IL}-8$, a cytokine whose expression is controlled by $\mathrm{C} / \mathrm{EBP} \beta$ [35]. C/EBP $\beta$ knockout mice are highly susceptible to Listeria monocytogenes infection [36], a Gram-positive bacteria that is recognised by Nod1 [34]. Mice deficient in RICK, a component of Nod1-signalling, also have a reduced ability to defend against Listeria monocytogenes [30]. Both RICK and C/EBP $\beta$ knockout mice have impaired Thelper 1 responses [30,37]. Together, these findings make investigation of the Nod1 response in the lungs of $C / E B P \beta$ knockout mice, and the immune responses to pathogens recognised by Nod1 in these animals, important future studies.

In conclusion, the current authors have demonstrated that the nucleotide-binding oligomerisation domain protein 1 receptor is expressed in mouse and human lung cells, including lung epithelial cells. Activation of nucleotide-binding oligomerisation domain protein 1 in the lung epithelial cell line BEAS-2B results in the activation of CCAAT/enhancer binding protein and nuclear factor- $\kappa \mathrm{B}$ transcription factors, both of which control expression of inflammatory cytokine genes. The involvement of CCAAT/enhancer binding protein factors represent a novel pathway downstream of nucleotide-binding oligomerisation domain protein 1 , highlighting the need for further investigations of the role that the CCAAT/enhancer binding proteins play in response to bacterial infection in the lung.

\section{ACKNOWLEDGEMENTS}

The authors are grateful for the technical assistance provided by A. Pettersson, and would like to than M. Malewicz (Ludwig Institute for Cancer Research, Stockholm, Sweden) for help with the luciferase measurements. The authors would also like to thank D. Mengin-Lecreulx and M. Hervé (Institute of Biochemistyr and Molecular and Cellular Biophysics, University of Paris South, Paris, France) for providing the TriDAP ligand, and L. M. Grønning and K. Taskén (Biotechnology Centre of Oslo, University of Oslo, Oslo, Norway) for the reporter gene constructs.

\section{REFERENCES}

1 Kawai T, Akira S. Pathogen recognition with toll-like receptors. Curr Opin Immunol 2005; 17: 338-344.

2 Chamaillard M, Hashimoto M, Horie Y, et al. An essential role for NOD1 in host recognition of bacterial peptidoglycan containing diaminopimelic acid. Nat Immunol 2003; 4: 702-707.

3 Girardin SE, Boneca IG, Carneiro LA, et al. Nod1 detects a unique muropeptide from Gram-negative bacterial peptidoglycan. Science 2003; 300: 1584-1587.

4 Inohara N, Ogura Y, Fontalba A, et al. Host recognition of bacterial muramyl dipeptide mediated through NOD2. J Biol Chem 2003; 278: 5509-5512.

5 Travassos LH, Girardin SE, Philpott DJ, et al. Toll-like receptor 2-dependent bacterial sensing does not occur via peptidoglycan recognition. EMBO Rep 2004; 5: 1000-1066.

6 Bals R, Hiemstra PS. Innate immunity in the lung: how epithelial cells fight against respiratory pathogens. Eur Respir J 2004; 23: 327-333.

7 Schmeck B, Moog K, Zahlten J, et al. Streptococcus pneumoniae induced c-Jun-N-terminal kinase- and AP-1dependent IL-8 release by lung epithelial BEAS-2B cells. Respir Res 2006; 7: 98-106.

8 DiMango E, Ratner AJ, Bryan R, Tabibi S, Prince A. Activation of NF- $\kappa$ B by adherent Pseudomonas aeruginosa in normal and cystic fibrosis respiratory epithelial cells. J Clin Invest 1998; 101: 2598-2605.

9 Escotte S, Al Alam D, Le Naour R, Puchelle E, Guenounou M, Gangloff SC. T cell chemotaxis and chemokine release after Staphylococcus aureus interaction with polarized airway epithelium. Am J Respir Cell Mol Biol 2006; 34: 348-354.

10 Lin Y, Zhang M, Barnes PF. Chemokine production by a human alveolar epithelial cell line in response to Mycobacterium tuberculosis. Infect Immun 1998; 66: 1121-1126.

11 Slevogt H, Schmeck B, Jonatat C, et al. Moraxella catarrhalis induces inflammatory response of bronchial epithelial cells via MAPK and NF-кB activation and histone deacetylase activity reduction. Am J Physiol Lung Cell Mol Physiol 2006: 290: L818-L826. 
12 Travassos LH, Carneiro LAM, Girardin SE, et al. Nod1 participates in the innate immune response to Pseudomonas aeruginosa. J Biol Chem 2005; 280: 36714-36718.

13 Kapetanovic R, Nahori MA, Balloy V, et al. Contribution of phagocytosis and intracellular sensing for cytokine production by Staphylococcus aureus-activated macrophages. Infect Immun 2007; 75: 830-837.

14 Slevogt H, Seybold J, Tiwari KN, et al. Moraxella catarrhalis is internalized in respiratory epithelial cells by a triggerlike mechanism and initiates a TLR2- and partly NOD1dependent inflammatory immune response. Cell Microbiol 2007; 9: 694-707.

15 Inohara N, Koseki T, del Paso L, et al. Nod1, an Apaf-1-like activator of caspase-9 and nuclear factor-кB. J Biol Chem 1999; 274: 14560-14567.

16 Bertin J, Nir WJ, Fischer CM, et al. Human CARD4 protein is a novel CED-4/Apaf-1 cell death family member that activates NF-кB. J Biol Chem 1999; 274: 12955-12958.

17 Cassel TN, Nordlund-Möller L, Andersson O, Gustafsson $\mathrm{J}-\AA$, Nord M. C/EBP $\alpha$ and C/EBP $\delta$ activate the Clara cell secretory protein gene through interaction with two adjacent C/EBP-binding sites. Am J Respir Cell Mol Biol 2000; 22: 469-480.

18 Berg T, Didon L, Nord M. Ectopic expression of C/EBP $\alpha$ in the lung epithelium disrupts late lung development. Am J Physiol Lung Cell Mol Physiol 2006; 291: L683-L693.

19 Akira S, Isshiki H, Sugita T, et al. A nuclear factor for IL-6 expression (NF-IL6) is a member of a C/EBP family. EMBO J 1990; 9: 1897-1906.

20 Grønning LM, Dahle MK, Tasken KA, et al. Isoformspecific regulation of the CCAAT/enhancer-binding protein family of transcription factors by $3^{\prime}, 5^{\prime}$-cyclic adenosine monophosphate in sertoli cells. Endocrinology 1999; 140: 835-843.

21 Girardin SE, Travassos LH, Herve M, et al. Peptidoglycan molecular requirements allowing detection by Nod1 and Nod2. J Biol Chem 2003; 278: 41702-41708.

22 Patrone C, Cassel TN, Pettersson K, et al. Regulation of postnatal lung development and homeostasis by estrogen receptor $\beta$. Mol Cell Biol. 2003; 23: 8542-8552.

23 Rodriguez-Martinez S, Cancino-Diaz ME, JimenezZamudio L, Garcia-Latorre E, Cancino-Diaz JC. TLRs and NODs mRNA expression pattern in healthy mouse eye. $\mathrm{Br}$ J Ophthalmol 2005; 89: 904-910.

24 Opitz B, Puschel A, Schmeck B, et al. Nucleotide-binding oligomerization domain proteins are innate immune receptors for internalized Streptococcus pneumoniae. J Biol Chem 2004; 279: 36426-36432.

25 Didon L, Ovarfordt I, Andersson O, Nord M, Riise GC. Decreased CCAAT/enhancer binding protein transcription factor activity in chronic bronchitis and COPD. Chest 2005; 127: 1341-1346.

26 Ramji DP, Foka P. CCAAT/enhancer-binding proteins: structure, function and regulation. Biochem J 2002; 365: 561-575.

27 Inohara N, Koseki T, Lin J, et al. An induced proximity model for NF- $\kappa$ B activation in the Nod1/RICK and RIP signaling pathways. J Biol Chem 2000; 275: 27823-27831.

28 Vidal VF, Casteran N, Riendeau CJ, et al. Macrophage stimulation with Murabutide, an HIV-suppressive maramyl peptide derivative, selectively activates extracellular signal-regulated kinases 1 and 2, C/EBP $\beta$ and STAT1: role of CD14 and Toll-like receptors 2 and 4. Eur J Immunol 2001; 31: 1962-1971.

29 Tsuchiya K, Toyama K, Tsuprun V, et al. Pneumococcal peptodoglycan-polysaccharides induce the expression on interleukin-8 in airway epithelial cells by way of nuclear factor- $\kappa \mathrm{B}$, nuclear factor interleukin-6, or activation protein-1 dependent mechanisms. Laryngoscope 2006; 117: 86-91.

30 Chin AI, Dempsey PW, Bruhn K, Miller JF, Xu Y, Cheng G. Involvement of receptor-interacting protein 2 in innate and adaptive immune responses. Nature 2002; 414: 190-194.

31 Kobayashi K, Inohara N, Hernandez LD, et al. RICK/Rip2/ CARDIAK signaling for receptors of the innate and adaptive immune systems. Nature 2002; 416: 194-199.

32 Descombes P, Schibler U. A liver-enriched transcriptional activator protein, LAP, and a transcriptional inhibitory protein, LIP, are translated from the same mRNA. Cell 1991; 67: 569-579.

33 Girardin SE, Tournebize R, Mavris M, et al. CARD4/Nod1 mediates NF- $\mathrm{KB}$ and JNK activation by invasive Shigella flexneri. EMBO Rep 2001; 2: 736-742.

34 Opitz B, Puschel A, Beermann W, et al. Listeria monocytogenes activated p38 MAPK and induced IL-8 secretion in a nucleotide-binding oligomerization domain 1-dependent manner in endothelial cells. J Immunol 2006; 176: 484-490.

35 Matsusaka T, Fujikawa K, Nishio Y, et al. Transcription factors NF-IL6 and NF- $\mathrm{B}$ synergistically activate transcription of the inflammatory cytokines, interluekin 6 and interleukin 8. Proc Natl Acad Sci USA 1993; 90: 10193-10197.

36 Tanaka T, Akira S, Yoshida K, et al. Targeted disruption of the NF-IL6 gene discloses its essential role in bacteria killing and tumour cytotoxicity by macrophages. Cell 1995; 80: 353-361.

37 Screpanti I, Romani L, Musiani P, et al. Lymphoproliferative disorder and imbalanced T-helper response in C/EBP $\beta$-deficient mice. EMBO J 1995; 14 : 1932-1941. 